\title{
O Papa João Paulo II e a Sagrada Escritura
}

\author{
Maria de Lourdes Corrêa Lima
}

Sendo a Escritura Sagrada fundamento indispensável da mensagem cristã, evidentemente, não poderia faltar ao Magistério do Papa João Paulo II referências a ela que, com o estudo sistemático permitissem depreender o modo como é lida e utilizada em seus ensinamentos. Também não seria sem interesse verificar quais temas bíblicos o Santo Padre tocou em seu Magistério e como o fez. Tal escopo, porém, escapa às possibilidades de tempo e finalidade da presente contribuição ${ }^{1}$. No curto espaço de tempo disponível, buscaremos delinear algumas perspectivas: (1) a importância da Escritura no Magistério de João Paulo II, (2) suas indicações acerca da utilização da Escritura na Igreja e, como tema de especial relevância, (3) a questão da interpretação da Escritura.

1. Quanto ao primeiro ponto, vale mencionar primeiramente que foi no governo de João Paulo II que foi promulgada a edição completa da Neo-Vulgata (25/4/1979). Mais do que este importante ato, porém, mostra-se evidente em seu magistério não só a abundante utilização da Escritura no desenvolvimento de seu pensamento, nos diversos tipos de documento que produziu, mas sobretudo o fato de que sua exposição toma a Escritura como ponto de partida para reflexão. Como exemplos, dentre tantos, temos a Encíclica Dives in

\footnotetext{
${ }^{1}$ Comunicação apresentada no painel comemorativo da beatificação do Papa João Paulo II. O painel teve lugar na PUC-Rio, em 25 de abril de 2011.
} 
Misericordia ${ }^{2}$; a Exortação Apostólica Reconciliatio et Paenitentia ${ }^{3}$ e a Carta Apostólica Salvifici Doloris ${ }^{4}$, que fazem grandes explanações sobre temas bíblicos. Neste e em outros documentos, o Papa recolhe dados levantados pelos estudos bíblicos e os une à interpretação feita pelos Santos Padres e outros escritores eclesiásticos. Mas particularmente percebe-se que sua explanação haure ainda de outra fonte, qual seja, sua própria leitura pessoal da Palavra de Deus. Ele não só expõe a Sagrada Escritura, mas o faz a partir de uma apropriação sua, pela reflexão sistemática e pela meditação e oração.

2. Fazem parte de seu magistério indicações fundamentais sobre a utilização da Escritura na Igreja, na formação do clero, dos leigos e pessoas consagradas, na pastoral (evangelização e catequese), no diálogo ecumênico e inter-religioso. Não seria difícil indicar aqui os diversos pontos abordados nos documentos que tocaram esta questão (por exemplo, Catechesi Tredendae (n. 27), Pastores dabo vobis (n. 11.34; 47: lectio divina; 5455: a Escritura nos estudos teológicos), Ut unum sint (n. 39.44.66 ). Basta no momento, contudo, citarmos alguns textos da Carta Apostólica Novo Millennio Ineunte (6/1/2001), onde o Papa traça os caminhos da Igreja no terceiro milênio, após a celebração do grande jubileu. Depois de apresentar como "núcleo essencial do grande legado" do jubileu a "contemplação da face de Cristo" (n. 15), no n. 17 afirma que esta "não pode inspirar-se senão naquilo que dele se diz na Sagrada Escritura, que está, do princípio ao fim, permeada pelo seu mistério"; "permanecendo ancorados na Sagrada Escritura, abrimo-nos à ação do Espírito, que está na origem de seus livros, e simultaneamente ao testemunho do Apóstolos". A Escritura, portanto, testemunha, em todas as suas páginas, o mistério de Cristo, que é a chave para sua compreensão. Não basta recorrer esporadicamente à Escritura, mas devemos "permanecer ancorados" nela. Então o mesmo Espírito que a inspirou age em nós e nós, por assim dizer, tocamos a própria experiência daqueles que conviveram com o Senhor Jesus.

Na terceira parte do mesmo documento, o Papa delineia um "programa"

\footnotetext{
${ }^{2}$ Onde o Papa explana largamente o tema da misericórdia divina no Antigo Testamento e no Novo Testamento (especial alusão à parábola do filho pródigo e à cruz de Cristo).

${ }^{3}$ Onde é apresentada particularmente a parábola do filho pródigo.

${ }^{4}$ Em especial os números 10-13 e 14-18, onde se expõe a mensagem do livro de Jó e o significado salvífico da cruz, com especial referência ao quarto cântico do Servo sofredor de Isaías (cf. Is 52,13 - 53,12).

${ }^{5}$ No n. 66, cita o texto conciliar Unitatis Redintegratio: "no (...) diálogo, a Sagrada Escritura é um exímio instrumento na poderosa mão de Deus para a consecução daquela unidade que o Salvador oferece a todos os homens".
} 
para "um novo impulso para a vida cristã" (n. 29). Este programa de renovação profunda da vida eclesial "só é concebível - diz o Papa - a partir de uma renovada escuta da Palavra de Deus": "escuta assídua", "leitura atenta", valorizando a Escritura "na oração pública da Igreja" e apoiando os "estudos teológicos e bíblicos" e sua utilização na evangelização e catequese, para as quais a Escritura tem aportado nova vida. O Papa chama particularmente a atenção para o valor inestimável da lectio divina: é a leitura orante que "permite ler o texto bíblico como palavra viva que interpela, orienta, plasma a existência” (n. 39). Esta mesma Palavra dá um novo impulso à evangelização: "alimentamo-nos da Palavra para sermos 'servos da Palavra"' (n. 40), diz o Papa.

Toca-se aqui o tema da atualização e inculturação da mensagem bíblica. Para João Paulo II, a Bíblia não pode ser reduzida a um produto cultural, pois, sendo Palavra de Deus, sua palavra, embora espelhe as culturas em que foi formulada, tem uma dimensão "absolutamente transcendente". E é exatamente por ser transcendente que ela é capaz de penetrar as diversas culturas, em diversos ambientes e épocas. Tal atualização e inculturação deve-se pautar pela "verdade dos conteúdos bíblicos". Num discurso dirigido aos participantes de um congresso sobre comunicação, o Papa chama a atenção particularmente para o fato de que novos meios de comunicação podem trazer grandes possibilidades para o contato com a Palavra de Deus (Discurso aos participantes no congresso sobre "Linguagem bíblica e Mass Media", 28/9/1998).

3. Grande relevância apresenta em seu pontificado a questão da interpretação da Escritura. Suas diretrizes são sintetizadas no discurso pronunciado quando lhe foi entregue o documento A Interpretação da Bíblia na Igreja, da Pontifícia Comissão Bíblica (23/4/1993), no qual o Papa avalia a aplicação do chamado método histórico-crítico na exegese e traça as orientações básicas nesta matéria. A colocação por escrito da Palavra de Deus foi um passo preparatório para o aparecimento da Palavra encarnada; por outro lado, após a ascensão de Jesus, é a palavra escrita meio privilegiado de o Senhor permanecer na comunidade dos fieis e, portanto, de comunhão com Deus (n. 6). Estas dimensões devem estar presentes na exegese. O intérprete da Escritura deve trabalhar considerando a dimensão divina da palavra humana e a realidade da encarnação da Palavra Eterna em expressões humanas. Isto exige a um tempo atenção à dimensão teológica da palavra e ao estudo histórico crítico (n. 7; 9). Pois, embora a Palavra de Deus seja absoluta, sua expressão humana é feita 
com as nuances e mesmo os limites das sociedades e personalidades que a geraram. As conquistas lingüísticas, literárias e hermenêuticas, bem como os elementos aportados por diversas ciências humanas podem contribuir para uma melhor compreensão dos textos (n. 8). Não esgotam, porém, o sentido da Escritura, pois a passagem necessária das palavras humanas à Palavra Divina não é feita senão levando em consideração a dimensão espiritual no trabalho interpretativo (n. 9) ${ }^{6}$. Na encíclica Fides et Ratio (1998), o Papa retoma rapidamente o tema, ao tratar da relação entre fé e razão na ciência bíblica (n. 94).

Este "método" de leitura é apresentado na catequese que dá início à explanação sobre os salmos da liturgia das horas (Audiência geral, 28/3/2001):

\begin{abstract}
"Nossa leitura terá sobretudo por finalidade evidenciar o significado religioso dos Salmos, mostrando como eles, mesmo tendo sido escritos há tantos séculos por crentes hebreus, podem ser incluídos na oração dos discípulos de Cristo. Por isso, deixar-nos-emos ajudar pelos resultados da exegese, mas por-nos-emos juntos na escola da Tradição, sobretudo escutando os Padres da Igreja" (n. 2).
\end{abstract}

A dimensão espiritual da Escritura se alcança colocando-se o trabalho exegético "na escola da Tradição", com particular atenção aos Santos Padres (cf. $D V 8.3 ; 23$ ).

Outro ponto especialmente enfatizado é a fidelidade à Igreja. Se a Escritura foi confiada à comunidade eclesial, para impulsionar a fé e a vida no amor, sua interpretação não pode desconsiderar a Igreja. Tal cuidadosa atenção não prejudica a objetividade, mas serve de quadro referencial (Discurso, n. 10). Aqui retorna a relação com a Tradição e é especificado o Magistério eclesial como aspecto essencial da exegese (cf. $D V$ 12).

Tal aspecto é considerado particularmente na segunda das quatro catequeses das quartas-feiras dedicadas à apresentação da Dei Verbum (pronunciadas em 24/4, $1^{\circ}, 8$ e 22/5/1985, dentro de um conjunto de catequeses dedicado ao Concílio Vaticano II). Tarefa da exegese é contribuir para a compreensão da Escritura e por isso é necessário que seu trabalho seja um

\footnotetext{
${ }^{6}$ É nesse sentido que o Papa diz: "Sim, para chegar a uma interpretação plenamente válida das palavras inspiradas pelo Espírito Santo, devemos nós mesmos ser guiados pelo Espírito Santo. Por isso é necessário rezar, rezar muito, pedir, na oração, a luz interior do Espírito e acolhê-la docilmente, pedir o amor, o único que torna o homem capaz de compreender a linguagem de Deus, que 'é amor' (1Jo 4,8.16). Durante o próprio trabalho de interpretação devemo-nos manter o mais possível na presença de Deus” (n. 9).
} 
serviço à fé, em consonância com a Fé da Igreja (a partir da íntima relação entre Escritura e Tradição). O Magistério, se de um lado utiliza os estudos exegéticos, ao mesmo tempo oferece a moldura dentro da qual este trabalho pode contribuir para o crescimento e aprofundamento da fé (cf. Audiência geral, 1\%5/1985, n. 6). A garantia da verdade vem não do estudo exegético mas da Igreja (isto é, do Magistério), que é a instância de interpretação autêntica do dado da fé (Ibd., n. 7). O Papa chama a atenção que também isto é um ato da "misericordiosa providência divina", pois evita subjetivismos e disputas acadêmicas naquilo que é dado essencial da fé e, dessa forma, garante ao povo de Deus a verdade da Escritura (cf. l.cit.).

Um aspecto de especial interesse aparece na primeira destas catequeses e é repetido no início da seguinte (respectivamente, 24/4 e 1\%/5/1985). Recorrendo a $D V 12$, o Papa explicita o sensus fidelium (consenso universal dos fieis, que inclui os Bispos junto com todo o povo de Deus), ao lado da Tradição, Escritura e Magistério, na interpretação e transmissão da Palavra de Deus:
"A tradição, a Sagrada Escritura, o Magistério da Igreja e o sentido sobrenatural da fé de todo o povo de Deus formam aquele processo vivificante, no qual a divina revelação é transmitida às novas gerações" (n. 7).

Tal elemento, embora entrevisto em DV $8^{7}$, não está enquanto tal tematizado no documento conciliar e, nesse sentido, apresenta certo aspecto de novidade. Como João Paulo II esteve profundamente inserido no trabalho do Concílio, deve ter conhecido as grandes dificuldades na elaboração da Constituição dogmática Dei Verbum. Somente a forma "E" (5a elaboração) chegou a produzir o texto que está no atual número 8 e que trata da Tradição. Já anteriormente tinham surgido fortes tendências de se integrar o tema da revelação ao documento sobre a Igreja (Lumen Gentium). Por isso, tanto maior foi a surpresa quando Paulo VI, no dia 4 de dezembro de 1963 declarou que a Revelação seria tema essencial da $3^{\text {a }}$ Sessão. A Comissão Teológica retomou o trabalho no dia 7 de março do ano seguinte, mas julgava necessário

\footnotetext{
7 "Esta tradição apostólica progride na Igreja sob a assistência do Espírito Santo. Com efeito, progride a percepção tanto das coisas como das palavras transmitidas, quer mercê da contemplação e estudo dos crentes, que as meditam no seu coração (cf. Lc. 2,19.51), quer mercê da íntima inteligência que experimentam das coisas espirituais, quer mercê da pregação daqueles que, com a sucessão do episcopado, receberam o carisma da verdade. Isto é, a Igreja, no decurso dos séculos, tende continuamente para a plenitude da verdade divina, até que nela se realizem as palavras de Deus" (grifo nosso).
} 
constituir uma Sub-Comissão de "peritos". Entre estes foram colocados L. Cerfaux, C. Colombo, Yves Congar, A. Grillmeier, K. Rahner, J. Ratzinger e outros. Esta Subcomissão trabalhou de 20 a 25 de abril e entregou os resultados à Comissão Teológica. Ratzinger, em seu comentário monumental a $D V^{8}$ diz que se percebe com evidência a mão de Congar $^{9}$ neste número 8 , onde a Tradição inclui "tudo aquilo que a Igreja é e tudo o que ela crê". João Paulo II, com referência a $D V 8$ e 12 em sua catequese das quartas-feiras, interpreta autenticamente o Concílio ao falar do "sensus fidelium" como fator essencial da grande Tradição.

Assim sendo, o Papa João Paulo II, como homem do Concílio que foi, vive em seu ensinamento a partir deste Concílio e o atualiza para os novos tempos. O testemunho da atualidade da Dei Verbum não deixa, nesse sentido, de ser um dos grandes legados de seu Magistério.

Maria de Lourdes Corrêa Lima

Professora do Departamento de Teologia da PUC-Rio Doutora em Teologia Bíblica pela Pontificia Università Gregoriana Professora do Instituto Superior de Teologia da Arquidiocese do Rio de Janeiro

Comunicação Recebida em 16/06/2011 Comunicação Aprovada em 02/08/2011

${ }^{8}$ Cf. Lexikon für Theologie und Kirche (ed. J. Höfer - K. Rahner), v. 13, Herder, Freiburg im Breisgau, $1967^{2}$, p. 519 A.

${ }^{9}$ Ratzinger refere-se diretamente ao segundo volume de Y. CONGAR, La Tradition et les traditions, Essai théologique, Fayard, Paris, 1963. 